\title{
THE EFFECTS OF SOME PESTICIDES ON REEF CORALS
}

$$
\text { by }
$$

\author{
AUSTIN E. LAMBERTS ${ }^{1)}$
}

\begin{abstract}
While investigating a reef coral kill in Samoa it was speculated that this might have been due to contamination by some chemical. Subsequently, scleractinian reef corals were tested to assess their reactions to 12 commonly used pesticides and toxic substances. The chlorinated-hydrocarbons such as DDT and Endrin produced stress effects in corals subjected to 2 ppm for 24 hours in in-vitro studies although the corals continued to deposit skeletal calcium. In-vivo tank experiments suggested that small amounts of these substances in seawater stimulated the corals to deposit skeletal calcium. Other pesticides were much less toxic to the corals.
\end{abstract}

1) 1520 Leffingwell, NE, Grand Rapids, Michigan, 49505, U.S.A. 